\title{
Familial Colorectal Cancer Type X
}

National Cancer Institute

\section{Source}

National Cancer Institute. Familial Colorectal Cancer Type X. NCI Thesaurus. Code C120084.

Hereditary nonpolyposis colorectal cancer characterized by the absence of germline mutations in DNA mismatch-repair genes. 